\title{
ENERGY EFFICIENCY OF HEAVY COMMERCIAL VEHICLES: ON ROAD FUEL CONSUMPTION SIMULATION TESTS FOR CITY APPLICATIONS WITH A TOWING TRAILER EQUIPPED WITH ELECTROMAGNETIC BRAKE.
}

\author{
Haraldo Rehder ${ }^{1}$ e Gustavo P. Rehder ${ }^{2}$ \\ Rehder Consultoria de Engenharia ${ }^{1}$ \\ Laboratory of Microelectronics - University of São Paulo² \\ rehder.consult@gmail.com ${ }^{1}$ \\ grehder@1me.usp.br ${ }^{2}$
}

\section{ABSTRACT}

There is a global trend for fuel consumption and emission tests in real conditions of application. On road fuel consumption measurements for heavy trucks are defined by SAE J1321 Standard. Papers have already been reported on road tests with a Towing Trailer with electromagnetic brake developed by the authors. The Trailer is authorized for circulation on public roads, has received the support of FAPESP in PIPE I Project and a Patent is under evaluation by INPI. Several applications were reported, such as evaluation of cooling systems, accelerated durability tests of powertrain and consumption tests on flat road at $20 \mathrm{~km} / \mathrm{h}$ and simulation tests up to $90 \mathrm{~km} / \mathrm{h}$ on road with up and downhills. Test programs on flat road simulating varied slopes at speeds up to $80 \mathrm{~km} / \mathrm{h}$ are ongoing. In this present study, the fuel consumption measurement of heavy trucks was demonstrated using a Towing Trailer with an electromagnetic brake. Since the electromagnetic brake can simulate different uphill slopes and loads, this concept can be used on a flat road to analyze fuel consumption of simulated city applications based on reproducible stop-and-go programs with speeds up to $60 \mathrm{~km} / \mathrm{h}$. 


\section{INTRODUCTION}

The global warming and energy efficiency have been discussed worldwide, including heavy commercial vehicles. The European Commission defined in the EU Climate strategies \& targets for 2030 a climate \& energy framework, which was adopted by EU leaders in October 2014. It was defined (from 1990 levels) [1] at least $40 \%$ cuts in greenhouse gas emissions, at least $27 \%$ share for renewable energy and at least $27 \%$ improvement in energy efficiency. In the USA, programs like the Super Truck I and II were defined [2]. Presently in Brazil, the program ROTA 2030 [3], not yet defined [4], will follow the InovarAuto Program, and will focus on a new industrial policy for the automotive sector, which includes gaseous emissions and energy efficiency for light and heavy vehicles. It includes several fields for the development of technologies concerning to vehicles such as: vehicle mass, resistive power (aerodynamics, ground contact) and load. Government actions prioritized until now, passenger cars and there are not yet clear defined actions or programs for heavy commercial vehicles.

There is a global trend for fuel consumption and emission tests in real conditions of application. On road fuel consumption measurements for heavy trucks are defined by SAE J1321 Standard [5] which has defined since 2002, evaluation tests of heavy trucks fuel consumption performed on road in real conditions of application. This shows, however, problems of repeatability due to changes of test conditions and especially due to road traffic. The results of consumption depend on the selection of the test road and are restricted to this test site. Therefore, they are not comparable to results in other roads with different topographic conditions

Developments on energy efficiency, emissions and fuel consumption for trucks and other heavy vehicles are usually performed on stationary devices and by computer simulations. For example, Everton Silva et al [6] focused on engine and peripheral elements: friction, advanced fuels (biofuels and high octane fuels), thermal management systems, auxiliary optimization (power steering, alternators, air conditioning) and energy recovery system.

In the big cities around the world, buses and trucks contribute heavily for their air pollution, so that many projects have been developed and should be tested. Optimization of Diesel engines, use of Biodiesel, gas, electrification and so on have been studied and proposed [7], [8] and [9]. Besides the stationary tests, there is a global trend for fuel consumption and emission tests in real conditions of applications, as presented for example by Xiaumeng Wu et all. [10] and in the AVL Handbook [11]. It is necessary therefore, to perform on road easily reproductive test to evaluate emissions, pollutions and energy efficiency. Those tests should be considered for city application, basically in stop and go programs. To perform those simulations, the authors suggest the use of a Towing Trailer with an electromagnetic brake. Development of test methodologies under real road condition can contribute for raising heavy commercial vehicles energy efficiency and lowering emissions. 


\section{METHODOLOGY: TOWING TRAILER WITH AN ELECTROMAGNETIC BRAKE}

Previous works were presented by the authors related to on road truck testing's using their own developed towing trailer (Figure 1) with electromagnetic brake (Figure 2) in various applications such as cooling evaluation, accelerated powertrain durability and fuel consumption. The Towing Trailer is authorized for circulating on public roads [12], a Patent is under evaluation by INPI [13] and has received the support of FAPESP in PIPE I Project [14]. Several applications were reported, such as evaluation of cooling systems [15], accelerated durability tests of powertrain [16] and consumption tests [17] and, [18]. The Towing Trailer was build up based on a 2 axle second hand sugar cane crop trailer and an electromagnetic brake acting over a rear axle with differential through a drive shaft which brakes the rear tires. An electric and electronic control cabin brings together all the measurements and control data and sends and receives Wi-Fi information to a laptop placed in the cab of the tractor truck. The forces between tractor truck and trailer are measured by a specially developed sensor with strain gauges that sends the signals to the laptop. New system based on strain-gauges was also developed for measuring the electromagnetic braking torque. The command and control during tests can be performed in the cab of the tractor vehicle and the data, can be logged on datasheets and allow the elaboration of graphics. The described equipment and methodologies allow different on road tests.

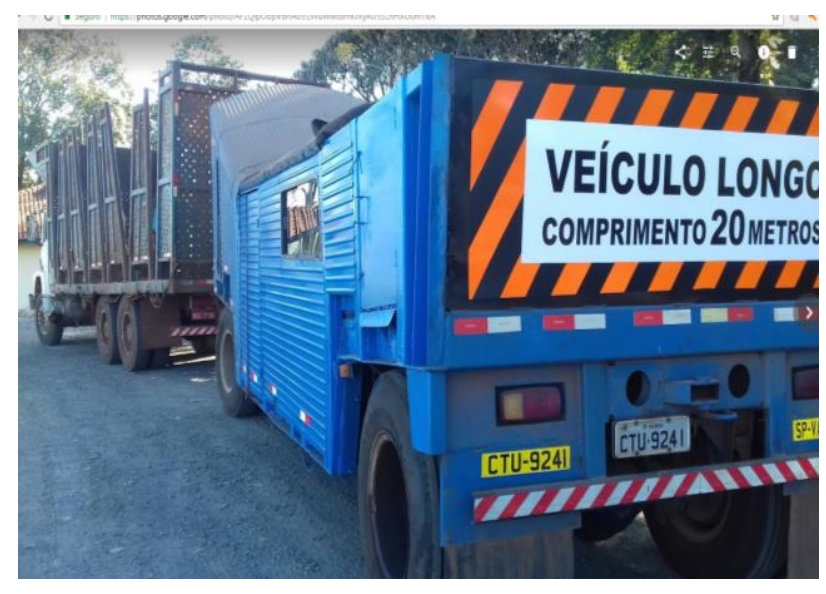

Figure 1. Towing Trailer being pushed by 6 x 4 Truck (back view).

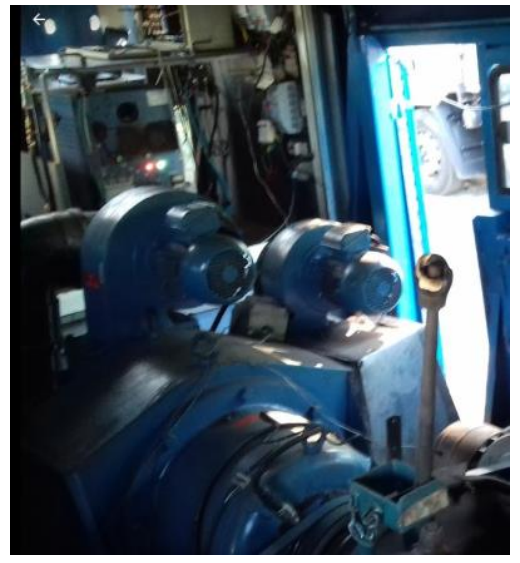

Figure 2. Towing Trailer inside. Electromagnetic Brake (EMB) and in background the electro-electronic cabin

\section{SIMULATIONS OF CITY APLLICATIONS}

\subsection{GPS}

In this present study, it was used a truck with high engine power of $420 \mathrm{HP}$, to evaluate the limits of the Towing Trailer. The results could be applied also to buses. The tests were performed on a flat road with laps of $2.000 \mathrm{~m}$ length with one 
roundabout on each end. There are predefined stops at every $1.000 \mathrm{~m}$. distance that means two stops per lap, and a maximal speed of $60 \mathrm{~km} / \mathrm{h}$.

A GPS placed on the roof of the truck supplies speed and position data to the lap top. Example of GNT Time, latitude, longitude and the route calculated by a laptop program, are presented on Figures 3 to 6 . A laptop program calculates the test distance too.

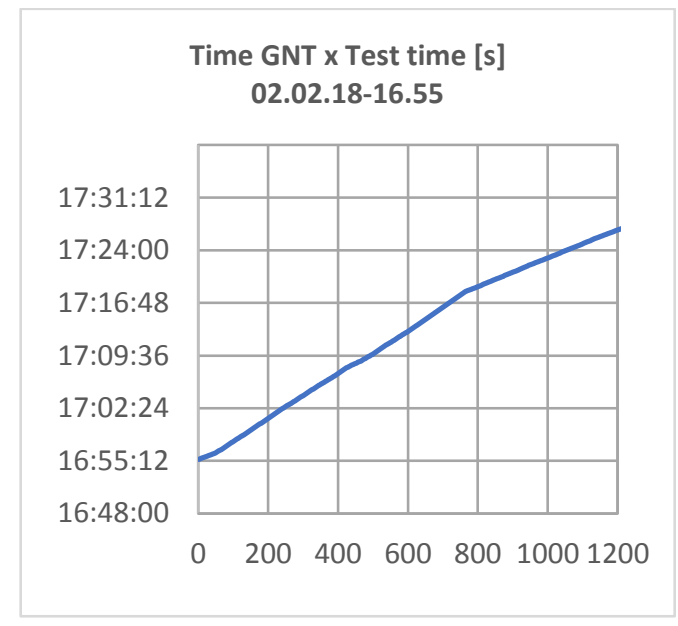

Figure 3. GNT Time in function of test time. Measure error by 800 s.

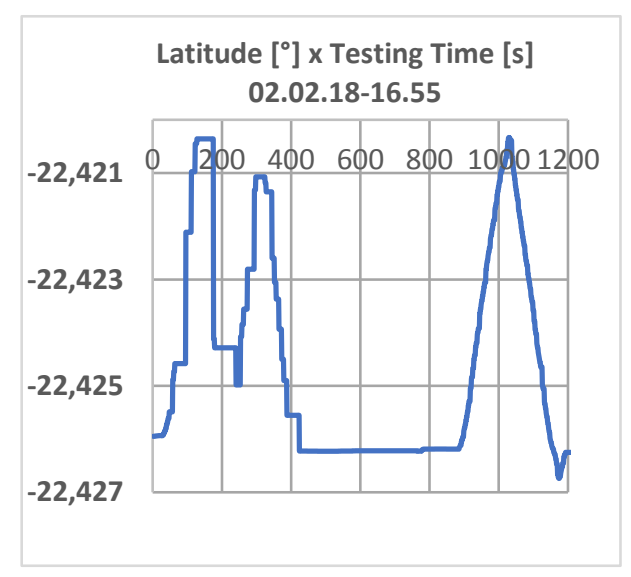

Figure 5. Latitude in function of Test time, got from GPS.

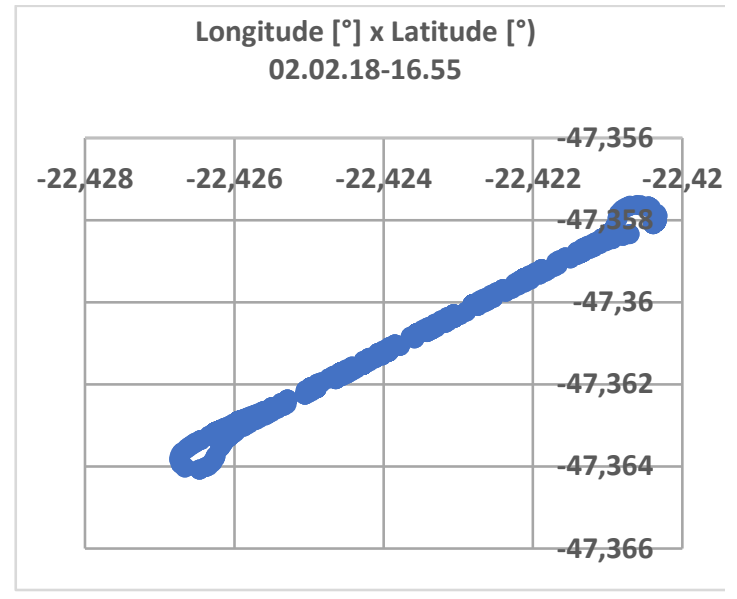

Figure 4. Route, calculated from Latitude $\mathrm{x}$ Longitude by the laptop (dynamic graphic).

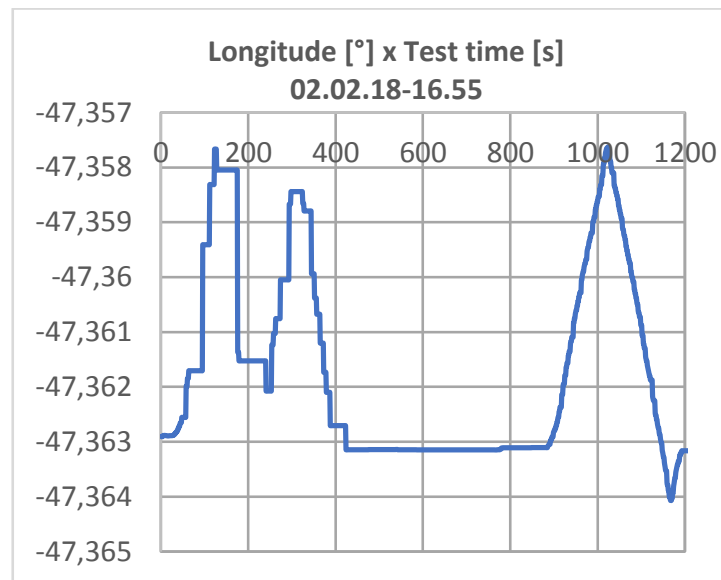

Figure 6. Longitude in function of test time, got from GPS

3.2 EMB (electromagnetic brake) current and rotation

Figure 7 shows extracts of the EMB current, simulating uphill of a new test on 16.03.18, beginning at 16.49. Figure 8 shows the EMB rotation, presenting 3 test cycles with 2 stops on each, and a longer stop from 150 to 384 s, for checking instrumentation. 


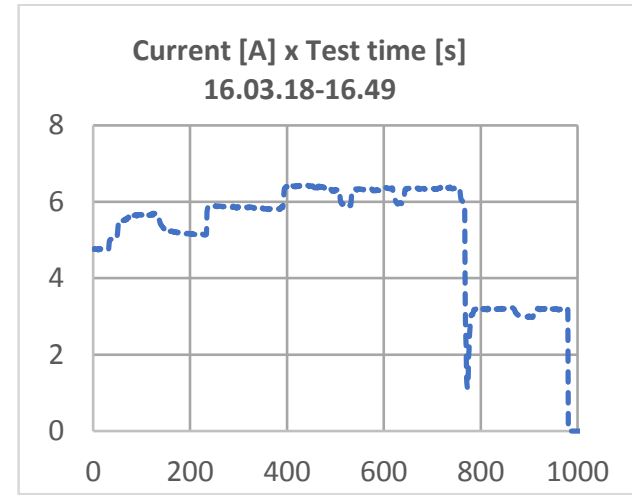

Figure 7. EMB Current program in function of Test time.

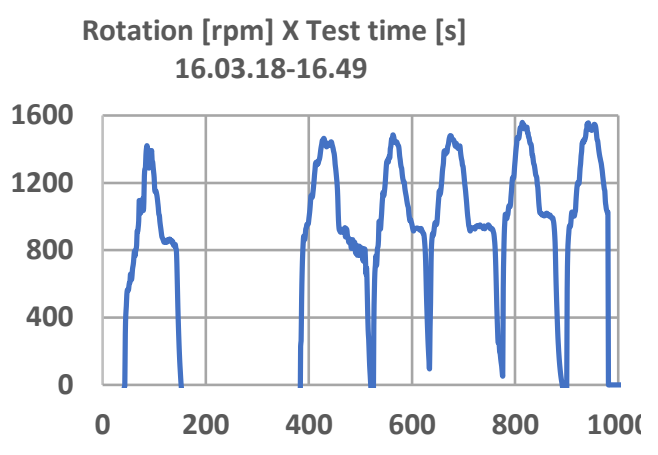

Figure 8. EMB Rotation in function of Test time. 3 cycles with 2 stops each.

\subsection{EMB temperatures and batteries tension}

Figure 9 shows the EMB system temperatures, used to turn on step by step the 3 ventilator motors and control the EMB temperature limits which basically depends on alternator and EMB rotation. Alternating segments with EMB current simulating uphill and without current, raise the testing capacity/limit.

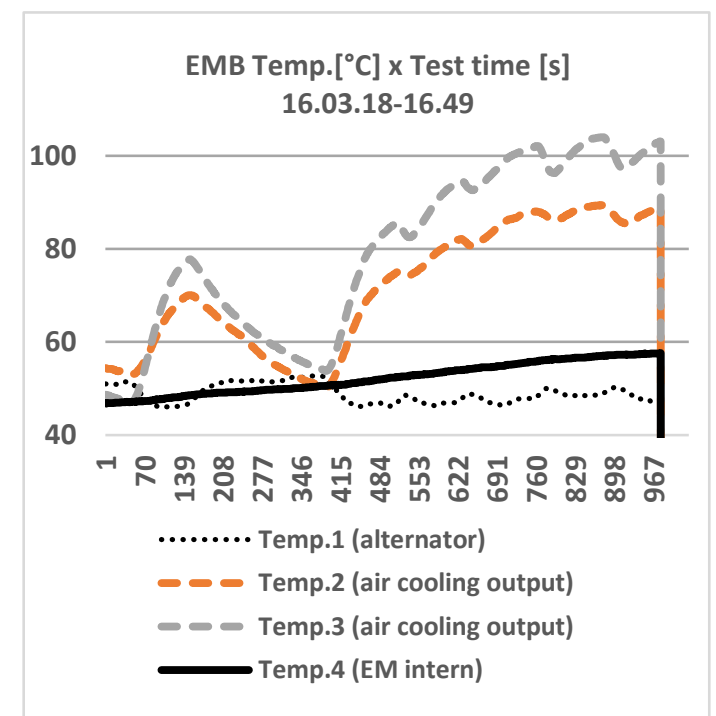

Figure 9. EMB System temperatures. At $60{ }^{\circ} \mathrm{C}$ the first ventilator motor turns on and stabilizes the temperatures 2 and 3.
Bateries tension [VDC] x Test time

[s]. 16.03.10-16.49

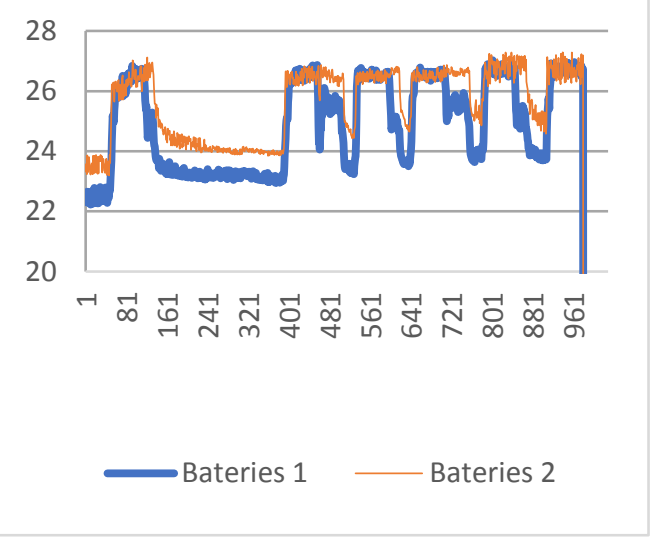

Figure 10. Batteries tension follow basically the EMB rotation. Batteries 1 supplies the EMB and batteries 2 the EMB cooling.

Figure 10 show the batteries tension. The batteries are supplied by 2 alternators, reaching almost 27 VDC during alternator and EMB rotation. Batteries 1 supplies the EMB and Batteries 2 supplies the EMB cooling ventilators. Based on those batteries 
charge results, it can be concluded that the energy supply of the system, alternators and batteries, is enough for braking and cooling during the movement of the convoy.

With the convoy and the alternator standstill, the EMB cooling capacity will have a limited actuating time. The limits should be defined in future for each application. It must be noticed the ecological advantage of this system, no external energy sources it doesn't need a complementary Diesel engine for example. The system uses the EM braking energy.

\subsection{Correlation of temperatures, EMB current, EMB rotation and batteries voltage}

In Figure 11, variables were presented in function of test time multiplied by convenient factors, to better compare the influences and relationship between them.

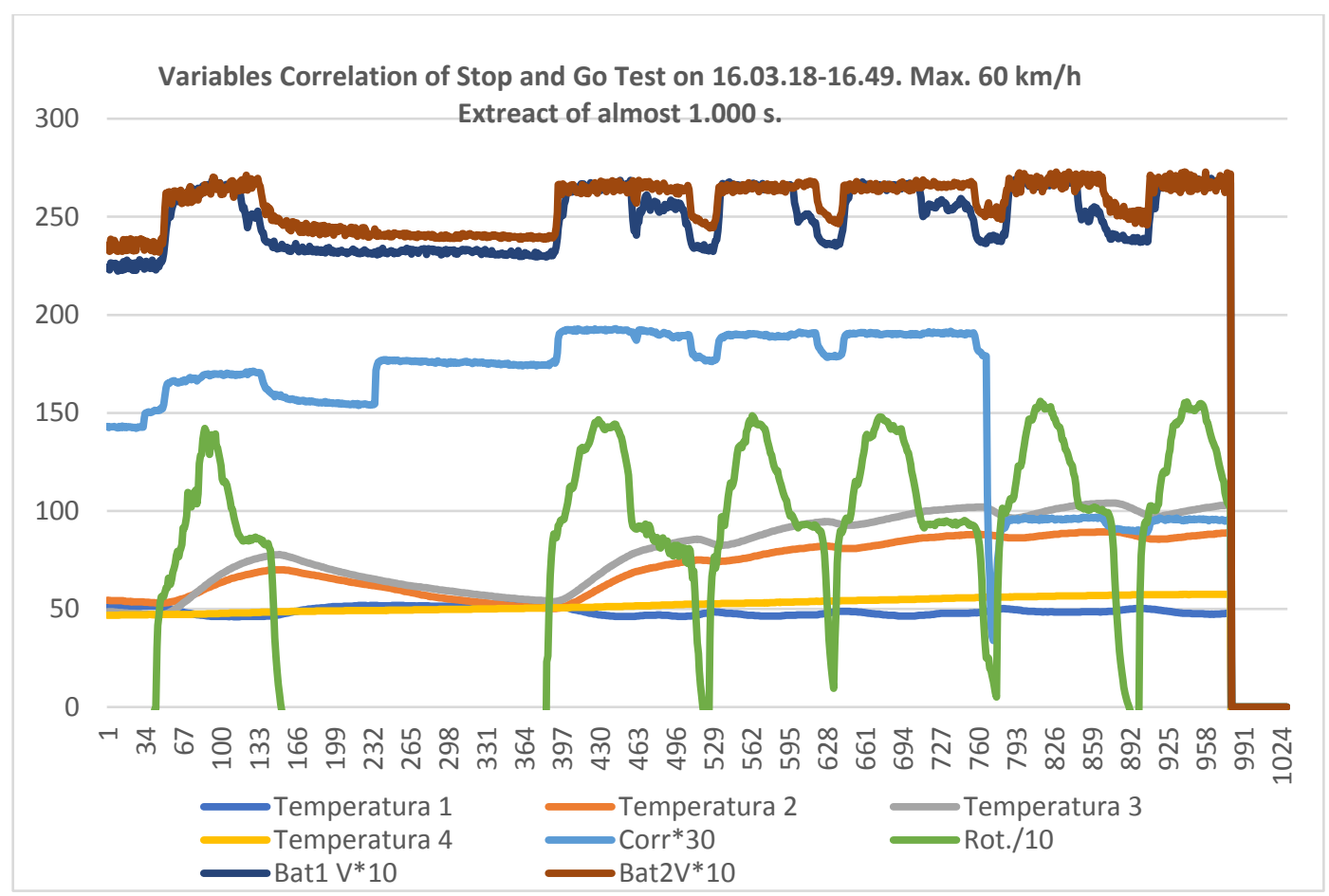

Figure 11. Correlation of variables multiplied by convenient factors to better compare them: EMB Temperatures, EMB current $* 30[\mathrm{~A} * 30]$, EMB rotation $[\mathrm{rpm} / 10]$ and batteries tension. [VDC*10].

The temperatures 1 and 2 raise up with the go and stop cycle, not reaching a critical temperature of almost $100^{\circ} \mathrm{C}$. Alternator Temperature 1 is stable and not critical, pointing to a good supply to the batteries, by rotation of the EMB and consequently of the alternator. The air cooling system is switched on at $60^{\circ} \mathrm{C}$ and the temperatures 1 and 2 stabilize. At lower current of $3 \mathrm{~A}$, the temperatures 2 and 3 tends to stabilize.

Batteries voltages begin with 22 and 24 VDC and raise up to 26/27 VDC by EMB elevated rotation, showing a good alternators performance. 


\subsection{EMB torque and traction force measurement}

Figures 12, 13 and 14 concerning a preliminary test 16.03.18-16.20, show the EMB rotation, and the effect of current on the forces between truck and Towing Trailer and the EMB torque. Besides the big signal oscillations on forces, caused probably by electronic interferences, many smaller oscillations appear and should be analyzed latter on. The effect on EMB torque will also be analyzed latter on.

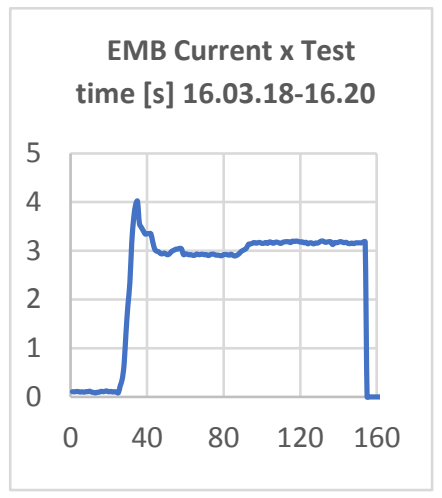

Figure 12. EMB current.

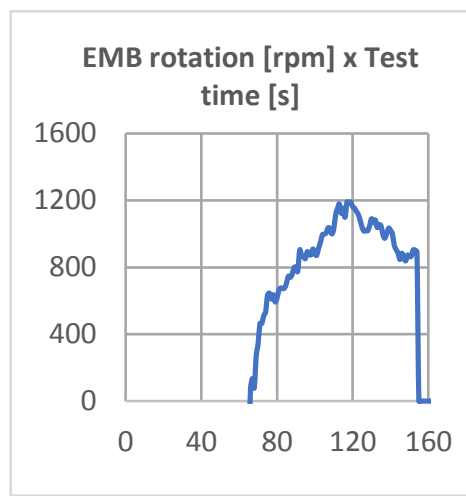

Figure 13. EMB rotation

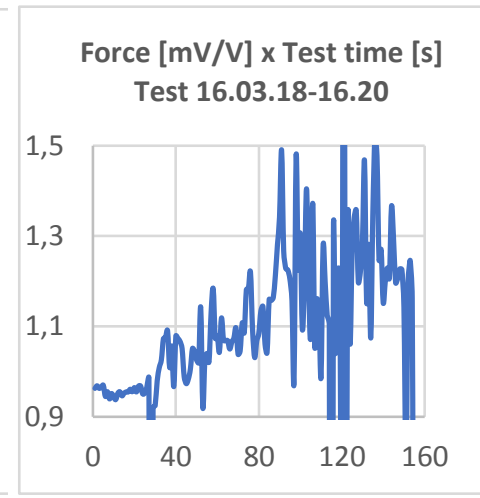

Figure 14. Force raises with rotation and current.

During the test 16.03.18-16.49, EMB torque and the forces between truck and Towing Trailer were measured and an extract of $1.000 \mathrm{~s}$ was shown in Figures 15 to 18.

Figure 15 shows the forces with high frequency signal oscillations due probably to electronic interference and/or convoy dynamic. The influence of the convoy dynamic seems very important, overlapping the EMB torque. In Figure 16, to clean up high frequency signal oscillations due to electronic and/or dynamic forces between truck and Trailer, it was used the average force values during $30 \mathrm{~s}$. Use of electronic filters should be tested in future measurements.

Figure 17 shows the EMB torque, with high frequency oscillations, which were filtered in Figure 18 by using the average torque value of 30 seconds. Use of electronic filters should be tested in future measurements. 


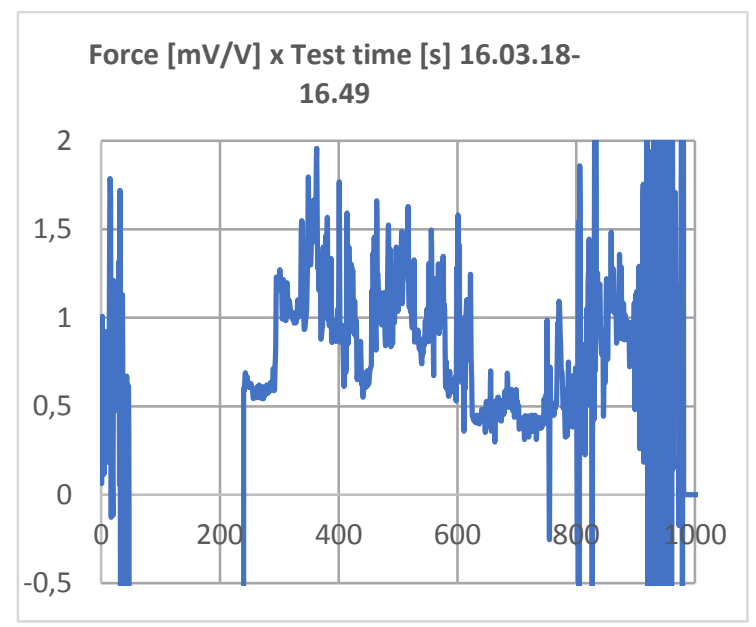

Figure 15. Force between truck and Towing Trailer. Signal failure up to $240 \mathrm{~s}$ and over $973 \mathrm{~s}$.

EMB Torque $[\mathrm{mV} / \mathrm{V}] \times$ Test time $[\mathrm{s}]$ 16.03.18-16.49

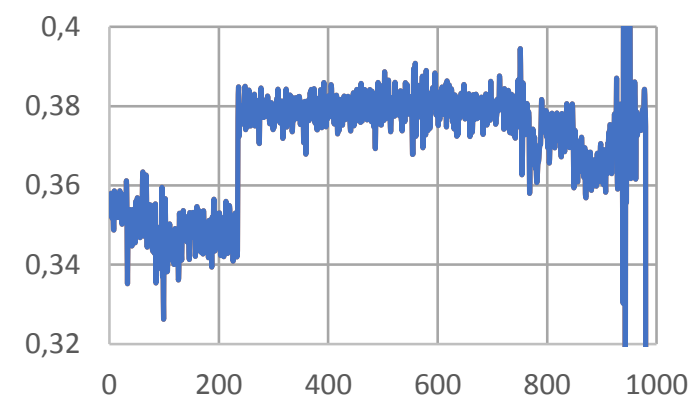

Figure 17. High frequency signal oscillation and failure over $937 \mathrm{~s}$. Note the influence of lowering current at $775 \mathrm{~s}$.

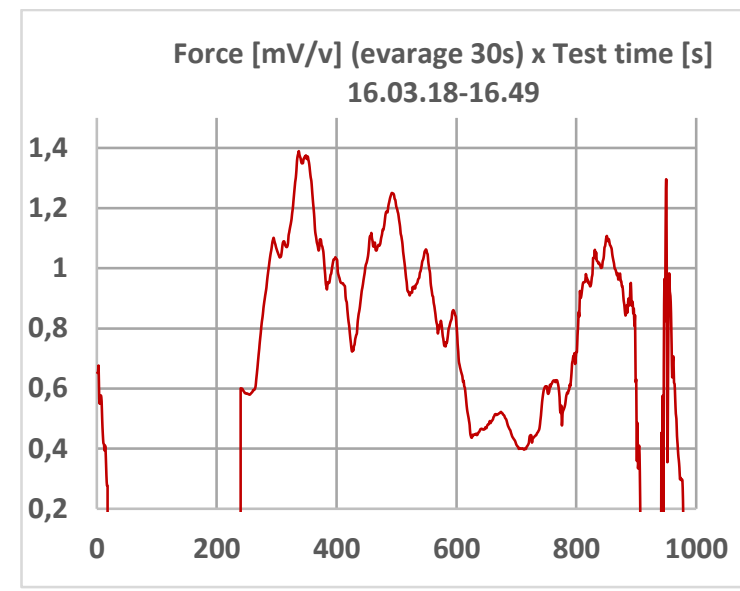

Figure 16. Force between truck and Towing Trailer. Same as Figure 13, but to clean up the high frequency oscillations, it was considered the forces average during $30 \mathrm{~s}$. Signal failure up to $240 \mathrm{~s}$ and over $973 \mathrm{~s}$.

Torque $[\mathrm{mV} / \mathrm{V}]$ (avarage 30s) x Test time [s] 16.03.18-16.49

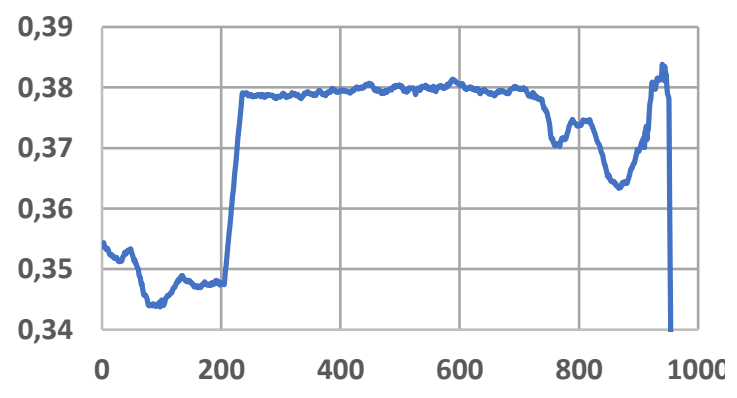

Figure 18. Average (during 30s) of torque signal, to clean up high frequency oscillations.

Figure 19 shows the correlation of variables multiplied by convenient factors, to better compare them: EMB current $[\mathrm{A} * 30]$, EMB rotation $[\mathrm{rpm} / 10]$, torque $[\mathrm{mV} / \mathrm{V} * 30$ and force $[\mathrm{mV} / \mathrm{V} * 10]$. Calculation of correlation factors between variables should be analyzed in future tests. 


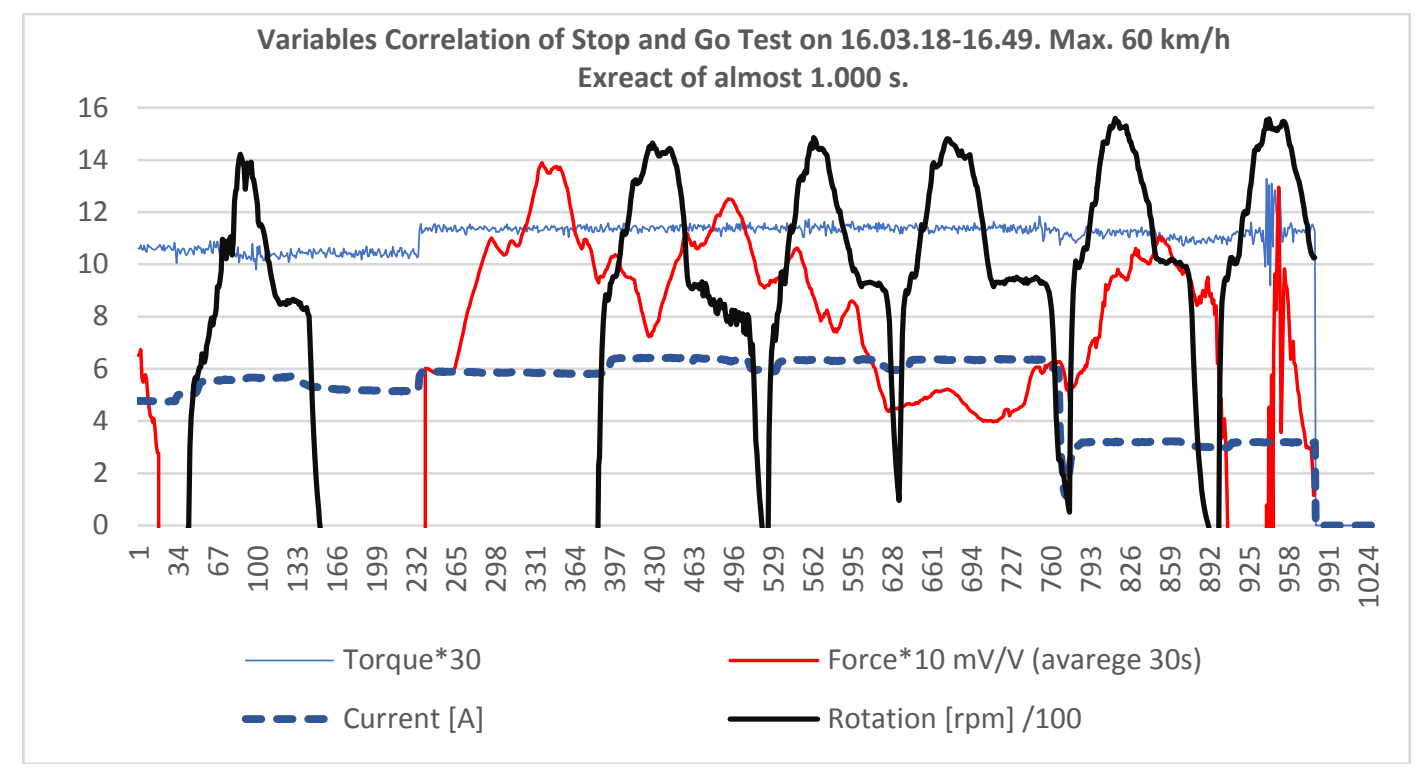

Figure 19. Correlation of variables multiplied by convenient factors to better compare them: Extract of almost $1000 \mathrm{~s}, 6$ cycles of go and stop.

\section{ON ROAD FUEL CONSUMPTION SIMULATION}

\subsection{Fuel consumption measurement}

As indicated before, fuel consumption methodology with the use of the Towing Trailer, on flat road at constant speed of $20 \mathrm{~km} / \mathrm{h}$ [17] and on open road, with up and downhills and maximal speed up to $90 \mathrm{~km} / \mathrm{h}$ [18] were presented in previous papers. Measurements of truck fuel tank level (for longer distances) as well as in an auxiliary small tank (for short distances) were described. Capacitive fuel level sensor was also used.

In this present paper fuel consumption measurements were performed as a simulation of heavy commercial vehicle in city applications, with a stop and go program. The measurements were performed in a flat road defined in Figures 5 to 7 with a convoy composed by a heavy $6 \times 4$ truck and the Towing Trailer. The tests were performed on 2,0 km laps, with roundabout on the edges and 2 stops just after those ones and maximal acceleration until reaching $60 \mathrm{~km} / \mathrm{h} ; 1.000 \mathrm{~m}$ was the distance between the stops.

New tests for simulation Energy Efficiency and Truck Fuel Measurements Performed with an Electromagnetic Brake Towing Trailer using a Reproducible Testing Program Simulating Sloped Roads at Speeds up to $80 \mathrm{~km} / \mathrm{h}$.

\subsection{Static fuel level calibration}

The main purpose of those previous and the present tests was to evaluate the use of the Towing Trailer, without evaluating deeply the fuel consumption measurement devices. Future tests can be performed with other methodologies like engine CAN 
data or fuel flow. In those tests, measurements were performed with a Fuel Level Sensor OMNICOMM LLS 20160, installed on the fuel tank filler neck. The present measured data are sent to the laptop and presented on desktop as shown in Figure 20. The measured fuel level can be calibrated in fuel level and fuel volume by a static calibration and is shown in Figure 21.

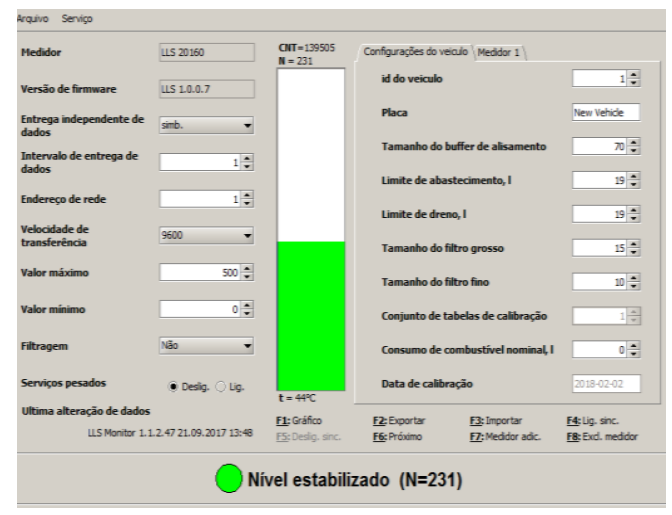

Figure 20. Desktop view. Example of the LLS 20160 fuel static level calibration.

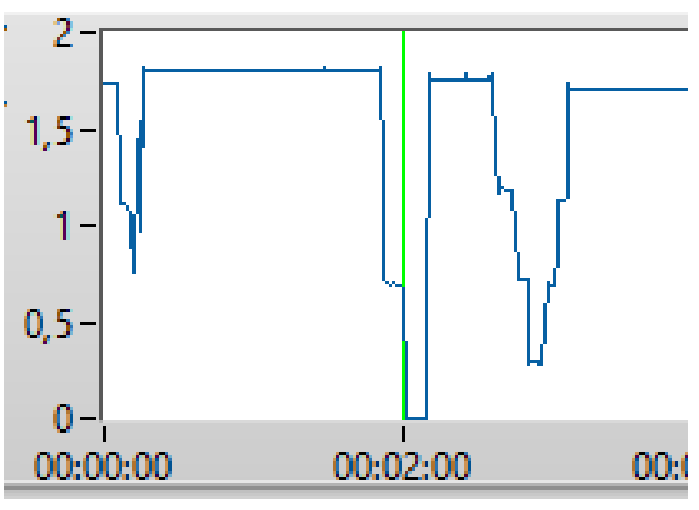

Figure 21. Desktop view. Example of LLS 20160 fuel static level calibration, steps of $5 \mathrm{~cm}$ fuel level.

\subsection{Dynamic fuel level measurements}

Fuel level measurements were performed on 16.02 .18 , beginning at $9^{\prime} 44$, with the capacitive sensor LLS 1620 and varied EMB current levels. Those level data were stored on the laptop test sheet and used for the diagram in Figure 22, showing an extract of $1.000 \mathrm{~s}$, corresponding to 5 test segments of go and stop. The convoy was accelerated at full truck engine power until reaching the speed limit of $60 \mathrm{~km} / \mathrm{h}$ and then maintained this speed until the next stop. The maximal EMB rotation was around $1600 \mathrm{rpm}$. The sensor does not measure correctly at low rotation. The fuel level shows huge oscillations with low frequencies, overlapped with smaller oscillations and higher frequency. Those higher frequency oscillations are probably caused by electronic interferences and can in future be filtered.

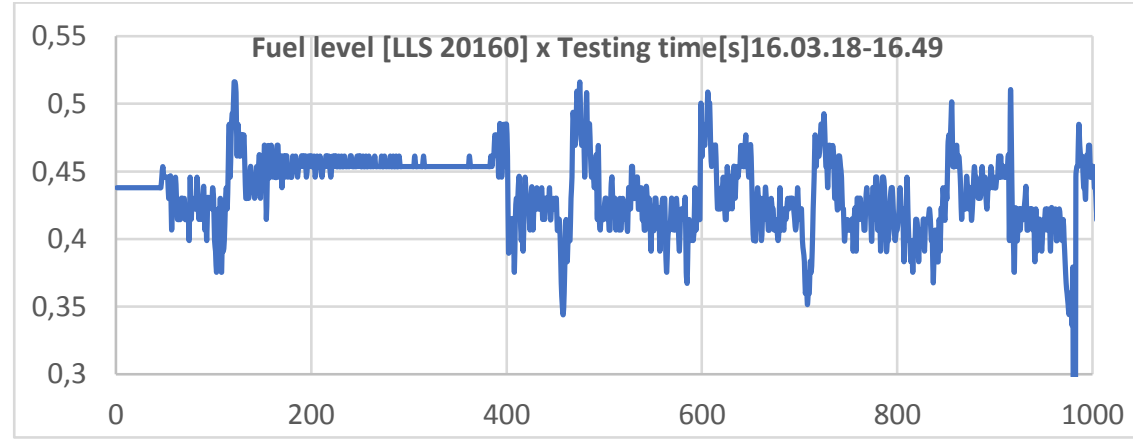

Figure 22. Fuel level measured by the LLS Sensor up to $1.000 \mathrm{~s}$ 
To analyze the fuel level behavior, it was presented the Figure 23, which compares the relationship of fuel level, EMB rotation and EMB current, multiplied by convenient factors to better show those relationships. It is possible to verify the low frequency huge oscillation during the acceleration and the deceleration of the convoy. It is possible to remark a certain stability of the level data by reaching the rotation (speed) peak and during the (short) standstill between the stop and go segments.

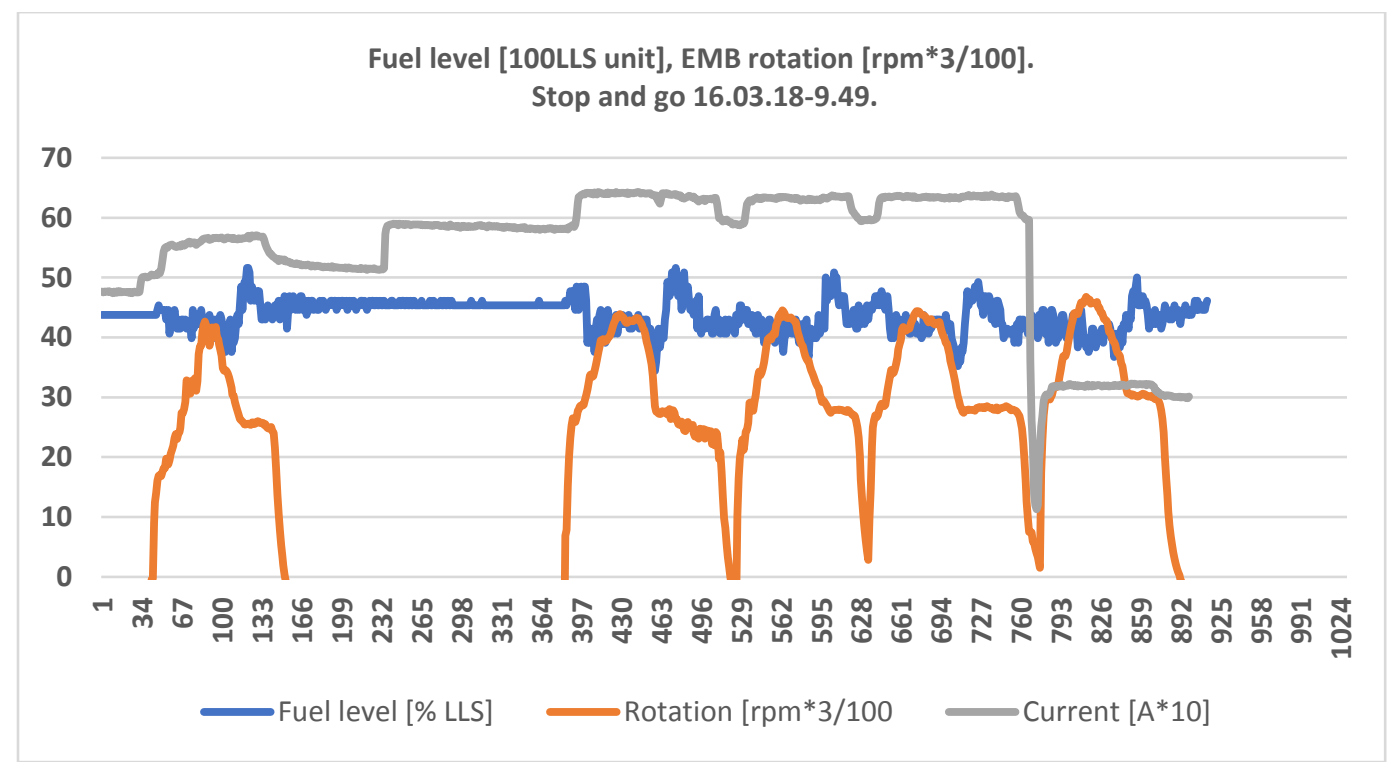

Figure 23. Correlation between current, EMB rotation and fuel level multiplied by convenient factors.

To evaluate measurements with the capacitive sensor LLS 1620, it was considered two more stable measurement points: at rotation peak and at convoy standstill during the period between two successive test segments. The results are shown in Figures 24 and 25 indicate a high variability of the method because the test distance was too short and therefore, the fuel consumption is low for the 300-liter fuel tank. (300 I fuel volume and $44 \mathrm{~cm}$ fuel level, correspond to $6,98 \mathrm{l} / \mathrm{cm}$ ).

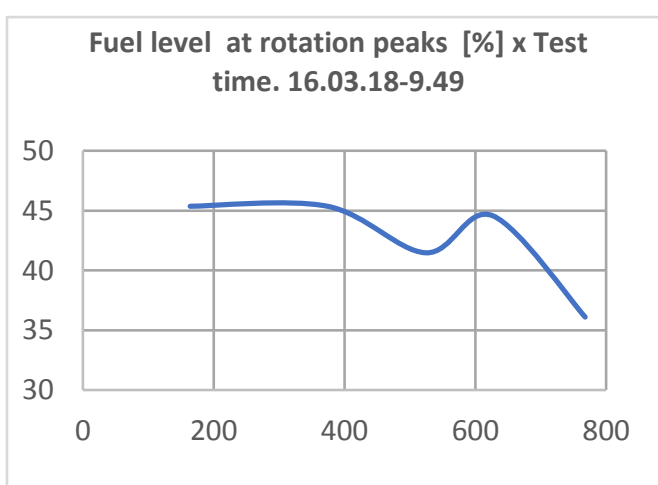

Figure 24. Fuel level at EMB rotation peaks, low precision due to short test distance.
Fuel level at truck standstils [\%]

$x$ Test time. 16.03.18-9.49

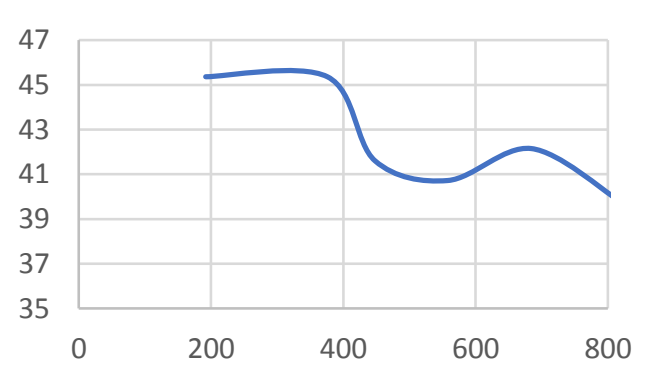

Figure 25. Fuel level at standstill, low precision due to short test distance. 
For longer distance tests, as for example the one used by the SAE J1321 Standard, a level measurement methodology with a capacitive sensor can be adequate. The use of a small auxiliary fuel tank with the capacitive sensor as presented in previous papers [17] and [18] will conduct to satisfactory results for short distances. It is expected that the use of the Engine CAN fuel measurements or fuel flux will certainly bring good results for short and long distances.

\subsection{On road fuel consumption simulation}

Previous papers and the ongoing tests indicates a very good possibility to use the Towing Trailer in many applications in on road tests, inclusive fuel consumption measurements.

In this present paper, it was presented with a truck and the Towing Trailer Prototype the simulation of a on road testing program to simulate city application, with stop and go (go and stop) segments. The preparation of the testing convoy is simple, as well the possibility of program variation as for example the stop distance and maximal speed. The EMB current simulates not only the slopes of the road but also the convoy load. It is possible to variate and compare easily the influence of the load of the convoy. Loading buses for testing will not be necessary.

The program, including simulation of road slopes and convoy load variation is easily reproductive. Test can compare results at sea level or up in the mountains. The present Towing Trailer Prototype do not allow simulation of downhills, but in future it's possible to develop a push-pull trailer with up and downhills simulation, like [20]. On road fuel consumption and in future, emission measurements can easily and reproductively be performed. Bus tests will be possible not only with alternative fuels but also with power trains with alternative energy.

It will be necessary to evaluate the test limits for each application, such as EMB temperatures, EMB current, stop and go program, traction vehicle power, the speed and so on. Alternating simulating uphill (with EMB current) with no current will allow tests with higher traction vehicle power. The stop time at standstill of the convoy should be as short as possible, because of no loading batteries by the alternators.

This stop and go on road simulation programs can be used in future as energy efficiency criteria for heavy commercial vehicle so as for emission tests, allowing comparisons of test results of different vehicles at similar conditions.

\section{CONCLUSIONS}

It is proposed evaluations of fuel consumption of heavy commercial vehicles in city applications based on reproducible programs of stop and go with the Towing Trailer with electromagnetic brake, simulating different programs with diverse uphills and different weights of the convoy. The Trailer can also be used for emission simulation 
tests of city buses, including alternative fuels. Continuity of the tests should be performed with support of bus and trucks producers, system developers, fuel producers, academic researchers and government departments connected with energy savings and legislation.

\section{REFERENCES}

1. EUROPEAN COMISSION, "Climate strategies, targets for 2030 climate \& energy framework by EU leaders", October 2014. https://ec.europa.eu/clima/policies/strategies/2030_en, Accessed March 2018.

2. US DEPARTMENT OF ENERGY, SuperTruck II, Vehicle Technologies Office Program Wide Selections to Accelerate the Development of Innovative Technologies", August 16, 2016. https://www.energy.gov/articles/energy-departmentannounces-137-million-investment-commercial-and-passenger-vehicle. Accessed March, 2018.

3. MINISTÉRIO DA INDUSTRIA, COMÉRCIO EXTERIOR E SERVIÇOS - MDIC, "Programa ROTA 2030", http://www.mdic.gov.br/competitividadeindustrial/principais-acoes-de-desenvolvimento- industrial/brasil-produtivo/acordosinternacionais

4. HIRATA,T. "Rota 2030 não está maduro e não tem prazo para sair, diz subchefe da Casa Civil", Folha de São Paulo, 12/03/2018.

5. SAE Standard, "Fuel Consumption Test Procedure - Type II". https://www.sae.org/standards/content/j1321_201202/. SAE Standard J1321_201202Rev. 2012-02-06.

6. Silva, Everton Lopes et all, "Motores Diesel - Metodologia de testes em bancos de provas", SIMEA 2017. DOI: 10.5151/engpro-simea2017-23.

7. CENTRO DE PESQUISAS EM EFICIÊNCIA ENERGÉTICA PROF. URBANO ERNESTO STUMPF, "Eficiência Energética e Biocombustíveis”, Workshop in FAPESP 28/11/2017.

8. UCS - UNION OF CONCERNET SCIENTIST, "Brief History of U.S. Fuel Efficiency Standards: Where we are and where we're going", https://www.ucsusa.org/, accessed April, 2018.

9. ANTP - AGENCIA NACIONAL DO PETROLEO, GAS NATURAL E BIOCOMBUSTÍVEL. "Biodiesel", http://www.anp.gov.br/biocombustiveis/biodiesel. Publicado 16 de Agosto de 2016, 16h21, Atualizado, 05 de Outubro de 2017, Acessed April. 2018.

10. XIAOMENGWU AND AL, "Real-world emissions and fuel consumption of diesel buses and trucks in Macao: From on-road measurement to policy implications", https://doi.org/10.1016/..atmosenv.2015.09.015. Elsevier.

11. AVL - Handbook 2016, "TYPE APPROVAL: EMISSION", page 24 and "HEAVY DUTY VEHICLES - CERTIFICATION" page 68, acessed March 2018, https://www.avl.com/documents/.../AVL+Handbook+2016

12. DETRAN - Departamento Transito de SP,"Certificado de Registro de Veículo", trailer registered for 20 tons, as CARRETA/REBOQUE/MEC. OPERACIONAL, CTU 29241/SP by the State Traffic Authority on Jan.3rd 2011. last License 2018. 
13. REHDER, H., "Reboque ou semirreboque de arrasto com freio eletromagnético para testes de veículos na Estrada". Request for Patent 0002221164838910 to INPIInstituto Brasileiro de Propriedade Intelectual, Brazilian Institute of Intellectual Property, published in Revista da Propriedade Industrial (RPI), Number 2213 on July 2013, published in EPO - European Patent Office (http://worldwide.espacenet.com), CPC Y02T10/7241 and IPC B60L7/00.

14. REHDER, H., "Testes de caminhões leves até semipesados com um reboque de arrasto inovador com freio eletromagnético para simulações on road de aclives", Project PIPE I, FAPESP 2013.

15. REHDER, H. and REHDER, GP, "On road cooling simulation tests of commercial vehicles performed by a trailer with electromagnetic brake", SIMEA 2015, DOI 10.5151/engpro-simea2015-PAP166.

16. REHDER, H. and REHDER, GP, “Accelerated Durability Tests of Commercial Vehicles Powertrains Performed on Road by a Towing Trailer with an Electromagnetic Brake", SAE 2015. DOI:10.4271/2015-36-0306.

17. REHDER, H. and REHDER, GP, "On road fuel consumption measurements in a truck at constant speeds using a towing trailer with electromagnetic brake", SIMEA 2017. DOI 10.5151/engpro-simea2015-PAP166.

18. REHDER, H. and REHDER, GP, "On Road Truck Fuel Consumption Measurements in Real Conditions of Application and Speeds up to $90 \mathrm{~km} / \mathrm{h}$, performed by a Towing Trailer with Electromagnetic Brake", SAE Technical Paper 2017-36-0109, 2017, https://doi.org/10.4271/2017-36-0109.

19. REHDER, H. and REHDER, GP. "Energy efficiency of heavy commercial vehicles: on road fuel consumption simulation tests in city applications with a Towing Trailer equipped with electromagnetic brake". Paper on working, to be presented in 2018.

20. BLOM, M., “ATP Push-Pull Trailer”. Alpine Simulation Testing, Automotive Testing Technology International. Soury, UK. September 2008. 